\title{
Professores que Foram Exemplos Acadêmicos
}

\author{
Teachers who were Academic Examples
}

\author{
Charles Mady ${ }^{10}$ \\ Universidade de São Paulo Faculdade de Medicina - Unidade Clínica de Miocardiopatias e Doenças da Aorta, ${ }^{1}$ São Paulo, SP - Brasil
}

Vivemos, ultimamente, em uma sociedade extremamente competitiva e individualista - características que tornam erros e defeitos mais aparentes. A pandemia na saúde, além das endemias de corrupção na política e no tecido social, levounos a uma tempestade perfeita. Seus estragos são de difícil solução, pois vários fatores são crônicos, enraizados, quase atávicos, presentes em todos os segmentos da sociedade. A solução chama-se educação. Como diz Paulo Freire, educado e respeitado, mas criticado por deseducados, a educação modifica os indivíduos, fazendo-os evoluir. Estes modificam a sociedade. É, portanto, projeto a longo prazo. ${ }^{1-3}$

Como já comentei em vários artigos na imprensa, temos recursos humanos de elevado nível moral e intelectual. Mas, com o atual sistema político, maligno, constituído por corporativismos e fisiologismos sólidos, que mandam, comandam e desmandam, bloqueia-se a evolução. Esse sistema criminoso retira de cena boa parte dos bemintencionados. Alguns conseguem vencer, superando os obstáculos, e fazem história, e deixam marcas positivas, tornando-nos mais educados e preparados para levar adiante os seus ensinamentos. Reconhece-se a qualidade pelos herdeiros, levando adiante a boa escola. O Instituto do Coração (InCor) é exemplo a ser seguido, tendo sido recentemente qualificado como um dos melhores hospitais públicos do mundo. É orgulho para nosso país.

Na Medicina, que é a minha seara, encontrei o que há de melhor e de pior referente ao ser humano. Quando a busca desenfreada por prestígio e dinheiro ocupa a mente de pessoas moralmente fracas, os maus exemplos se apresentam. Essa doença está aumentando em minha profissão, seguindo os passos de outros setores da sociedade. A palavra caráter está aos poucos sendo erodida. No entanto, com otimismo, vamos lembrar aqueles que seguiram a cartilha de Paulo Freire, formando e educando no bom caminho, levando nossa Medicina ao reconhecimento internacional. Tive exemplos memoráveis que marcaram minha formação, dando lições de humildade e de sabedoria. Não perseguiam holofotes, pois a profissão era um fim, e não um meio. Tomo a liberdade de citar alguns, com os quais tive relação direta.

\section{Palavras-chave}

Educação Médica; Docentes; Sociedades Médicas; Hospitais Públicos; Faculdades de Medicina.

Correspondência: Charles Mady •

Universidade de São Paulo Faculdade de Medicina - Unidade Clínica de Miocardiopatias e Doenças da Aorta - Av. Dr. Enéas de Carvalho Aguiar,44. CEP 01246-903, São Paulo, SP - Brasil

E-mail: charles.mady@incor.usp.br

DOI: https://doi.org/10.36660/abc.20201161
No início de meu curso, em 1965, na Faculdade de Medicina da Universidade de São Paulo (USP), fui aluno de Odorico Machado de Sousa, sempre presente, que conseguia transformar o difícil curso de anatomia em algo prazeroso. Permanecia - ele e sua equipe - diariamente conosco, pronto a responder a qualquer dúvida. Era exigente, e nos ensinou a enxergar sua matéria de forma construtiva, valorizando-a e relacionando-a às outras disciplinas. Transformou a rejeição em aprendizado. Portanto, nos educou. Em meu quarto ano, conheci Luiz Décourt e Euryclides de Jesus Zerbini, acadêmicos na definição exata da palavra. Fizeram escola internacional, com incontáveis discípulos, que se tornaram líderes em seus locais de origem, e em nossa universidade. Faziam questão de, pessoalmente, ensinar, mantendo socraticamente proximidade com os alunos. A finalidade primordial era a faculdade. Construíram, com suas equipes por eles educadas, o InCor, elevando ainda mais o conceito da USP. Deixaram uma herança reverenciada até hoje. Foram reais Professores, com P maiúsculo. Seus alunos têm orgulho de terem sido seus discípulos.

Décourt foi sucedido por Fulvio Pileggi, que dedicou todo o seu prestígio e força política para engrandecer ainda mais o InCor. Portador de um caráter exigente, solicitava pessoalmente doações à sociedade, pois a verba pública era insuficiente para realizar seu projeto. Estimulava a assistência, o ensino e a pesquisa, sabendo que esses eram os determinantes de qualidade acadêmica. Cobrava pessoalmente resultados, com presença constante no InCor. Deixava a porta sempre aberta. Sua rigidez escondia um coração incapaz de guardar mágoas. Macruz e Tranchesi, também discípulos de Décourt, foram seus colaboradores, acadêmicos do mais elevado nível, e que também muito nos ensinaram. Hoje, seus herdeiros estão à altura dos mestres. ${ }^{4}$

Em viagens por este país, tive a oportunidade de conhecer centros universitários que me impressionaram pelo enorme potencial cultural. O falecido Prof. Pareto, da Universidade Federal Fluminense (UFF), foi exemplo de humildade e sabedoria, tendo muito me marcado. Fez escola, ensinando a ver, ouvir e entender humanamente o paciente, antes de exames e telas. Formou herdeiros brilhantes, que o sucederam. Reconhece-se o mestre por seus produtos.

Quantos há mais, pouco conhecidos, e muitas vezes pouco valorizados, espalhados por aí? Temos que aprender a reconhecer valores e méritos. Esses poucos exemplos servem para mostrar que podemos ter um futuro melhor com vontade política, partindo de dirigentes educados e determinados. Os mestres em todas as matérias estão aí, na difícil tarefa de educar. Aliviem os obstáculos. Deixe-os mostrar seus valores. Temos que aprender a reconhecê-los e cultuá-los. Como costumo dizer, quem não cultua os Mestres jamais será um Mestre. 


\section{Carta ao Editor}

\section{Referências}

1. Mady C. Medical education in Brazil. Arq Bras Cardiol.2009;93(4):e70-1, e58-9.

2. Mady C. A saúde de nossas universidades.(estadão.com.br) (internet) [Citado em 2021 apr 10] Disponível em :https:/opniao.estadao.com.br/noticias/ espaco-aberto a -saude-de-nossas-universidades,70003109850
3. Mady C. As sociedades médicas e as universidades publicas. Arq Bras Cardiol.2019;112(3):317-8

4. Mady C. Luiz V Décourt, ícone do humanismo científico. Clinics. 2007;62(4):375-6. 